\title{
A Clearly Observable Cold Fracture Line of an Early Occult Hip Fracture on Bone Scintigraphy
}

\author{
Zhiyun Yang, Tameron Reed, and Alberto A. Simoncini \\ Department of Radiology, Louisiana State University Health Sciences Center, Shreveport, Louisiana
}

\begin{abstract}
Although a true fracture is commonly associated with increased radionuclide uptake on bone scintigraphy, it is also possible for an area with no increased uptake (a cold line) to indicate fracture, as demonstrated in this case study. Detection of an occult acute hip fracture through recognition of a cold fracture line is important because of the associated therapeutic, economic, and medicolegal implications.
\end{abstract}

Key Words: joint/muscle; SPECT; bone scintigraphy; cold line; occult fracture; subcapital neck fracture

J Nucl Med Technol 2014; 42:116-117

DOI: 10.2967/jnmt.113.130765

$t$ is common on bone scintigraphy for a true fracture to be associated with increased radionuclide uptake. Furthermore, the appearance of an area with no increased uptake (a cold line) is commonly considered to be negative for a fracture. This case study demonstrates a clearly observable cold hip fracture line on a bone scintigram. This finding will be helpful for diagnosing an early occult hip fracture to avoid unnecessary and potentially disastrous sequelae.

\section{CASE REPORT}

A 69-y-old man (who gave permission to use the data from his studies for our article) presented with a history of colon cancer, thyroid cancer, and advanced prostate cancer. He came to the emergency room after a fall while walking to his bed. He complained of pain in his left hip. An anterior-posterior radiograph of the pelvis was interpreted as negative for a fracture. A bone scintigram was ordered $4 \mathrm{~d}$ after the fall. Three hours after intravenous administration of $740 \mathrm{MBq}(20 \mathrm{mCi})$ of ${ }^{99 \mathrm{~m}} \mathrm{Tc}-$ methylene diphosphonate, a whole-body bone scintigram (Fig. 1) and spot views of the pelvis (Fig. 2) were obtained using a Symbia SPECT camera (Siemens). A repeated pelvic radiograph, MR imaging of the left hip (Fig. 3), and radiographs of the

Received Aug. 10, 2013; revision accepted Nov. 4, 2013.

For correspondence or reprints contact: Zhiyun (Jane) Yang, LSU Health Sciences Center, 1501 Kings Highway, P.O. Box 33932, Shreveport, LA 71130 .

E-mail: zyang@Isuhsc.edu

Published online Feb. 20, 2014.

COPYRIGHT (c) 2014 by the Society of Nuclear Medicine and Molecular Imaging, Inc. thoracolumbar spine were collected on the basis of the recommendation from the bone scan. The patient underwent an open-reduction internal fixation of the left hip fracture $9 \mathrm{~d}$ after the fall.

\section{DISCUSSION}

The whole-body bone scintigram revealed a clearly defined linear area of no uptake, or the so-called cold line, crossing the left femoral neck (Fig. 1). This cold line was felt to be suggestive of a fracture. However, given that the typical appearance around a fracture site on bone scintigraphy is an increase in tracer uptake, we were hesitant to

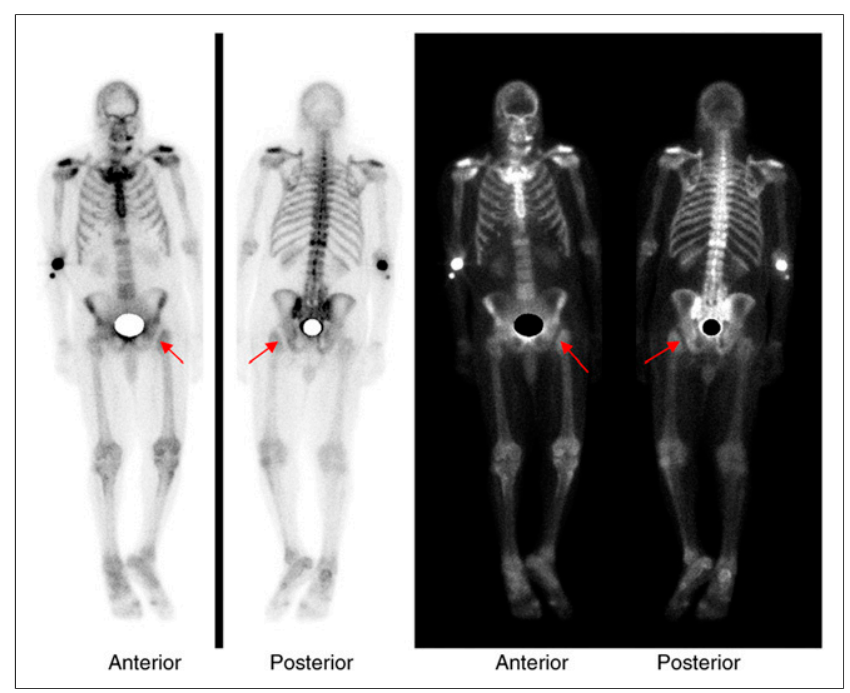

FIGURE 1. Same whole-body bone images displayed with white background on left and black background on right to define lesion better. These images reveal clearly defined cold fracture line (arrows) crossing left femoral neck.

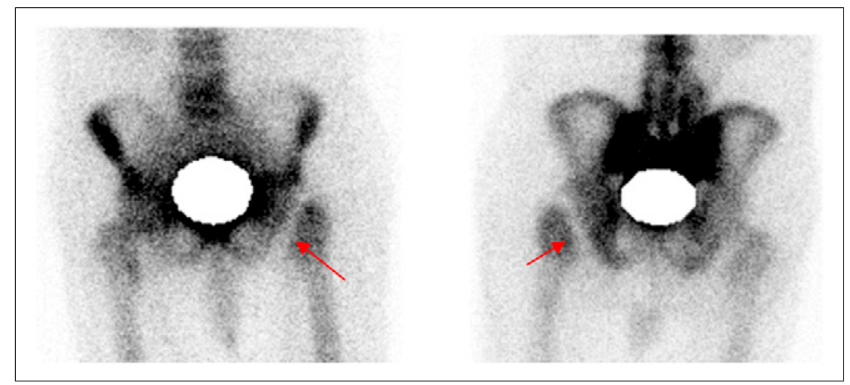

FIGURE 2. Anterior (left) and posterior (right) views of pelvis reveal clearly defined cold line crossing left femoral neck. 


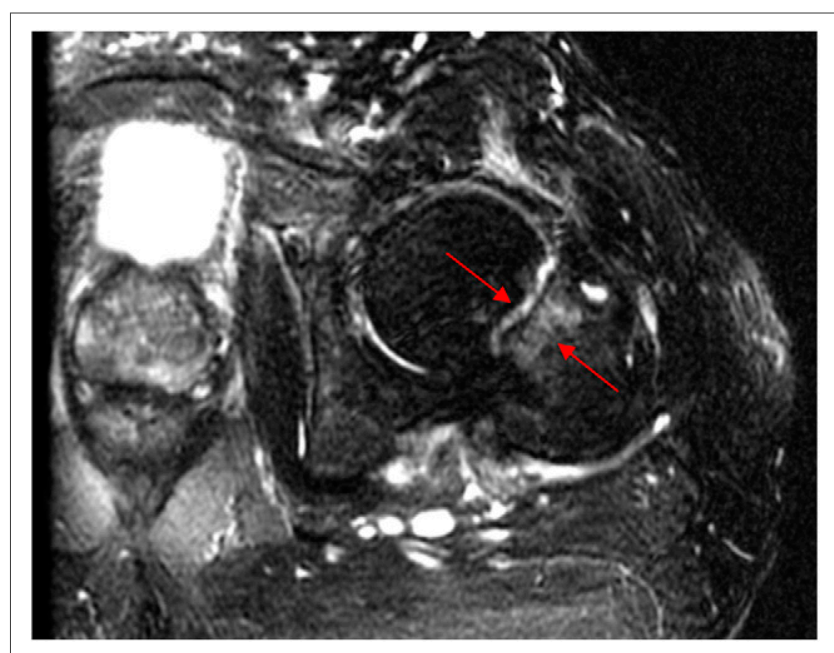

FIGURE 3. T2-weighted fat-saturated MR axial view of left hip demonstrates left subcapital femoral neck fracture with associated bone marrow edema (arrows).

unambiguously diagnose our observations as a true fracture. After ruling out any possibility of a secondary cause for the cold line (an external object lying on the patient within the viewing area), additional spot views of the pelvis (Fig. 2) were obtained. These again revealed the obvious cold line in the same location. Because of that finding, we increasingly suspected a fracture, despite the lack of obvious tracer uptake. The repeated anterior-posterior pelvic radiograph provided additional evidence for a fracture line across the left femoral neck. MR imaging of the left hip further confirmed a left subcapital femoral neck fracture with associated bone marrow edema (Fig. 3). We also observed increased tracer uptake at the T12 vertebra (Fig. 1) from the whole-body bone scintigram (this uptake was absent from a bone scintigram before the fall [Fig. 4]). The T12 observation was thought to be related to the fall and not a metastatic lesion. Radiographs of the spine (not shown) revealed an acute compression fracture of T12.

It is reported and commonly accepted that on scintigraphy, an acute hip fracture typically appears as a generalized diffuse increase in radionuclide activity around the fracture site. Although the mechanism of ${ }^{99 \mathrm{~m}} \mathrm{Tc}$-labeled phosphate accumulation around a fracture is unclear, theories include hyperemia, inflammation, increased metabolic rate, and bone repair (1-4).

Prior bone scintigram observations of false-negative cold fracture areas $(2,3)$ of the hip have been reported. In those reports, the areas were in the femoral head or neck region but showed no localized increased uptake to suggest a fracture. In two of the cases these observations initially were considered to represent an avascular femoral head (3) but were later proven to be hip fracture. Fortunately, in our case a clear cold line in the femoral neck was demonstrated on the bone scintigram and could easily be connected with a diagnosis of fracture even in the absence of increased activity.

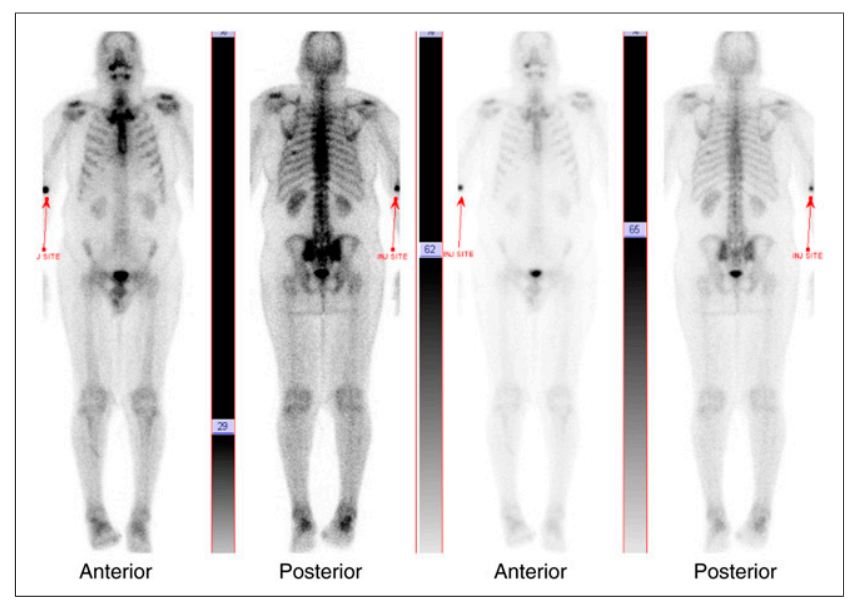

FIGURE 4. Same whole-body bone images displayed with more intensity on left than right to define different lesions better. These images taken in 2009 demonstrated no scintigraphic evidence of osseous metastasis or fracture in T12 and no cold fracture line seen in left hip. Arrows indicate injection site.

The reason for the lack of increased uptake around a fracture site is not clearly understood. It has been suggested that in older osteoporotic patients, significant focal accumulation of activity may not occur until $72 \mathrm{~h}$ after injury (5). Our patient had severe osteoporosis.

\section{CONCLUSION}

A cold fracture line on bone scintigraphy cannot always be ruled out as an early fracture, particularly with availability of improved $\gamma$ cameras that clearly show such an appearance. Further evaluation is needed because early detection of occult fractures of the hip has important therapeutic, economic, and medicolegal implications. Bone scintigraphy has proven to be a highly sensitive and specific method of detecting an occult fracture at an early stage (2). The reported percentage of increased activity around a hip fracture site is $80 \%$ at $1 \mathrm{~d}$, $95 \%$ at $3 \mathrm{~d}$, and $98 \%$ at $1 \mathrm{wk}(1)$. Awareness of the possibility of a cold fracture line will increase opportunities to detect an occult acute hip fracture by bone scintigraphy.

\section{DISCLOSURE}

No potential conflict of interest relevant to this article was reported.

\section{REFERENCES}

1. Mettler FA, Guiberteau MJ. Essentials of Nuclear Medicine Imaging. 5th ed. Philadelphia, PA: Saunders-Elsevier; 2006:269-270.

2. Holder LE, Schwarz C, Wernicke PG, et al. Radionuclide bone imaging in the early detection of fractures of the proximal femur (hip): multifactorial analysis. Radiology. 1990;174:509-515.

3. Lewis SL, Rees JI, Thomas GV, et al. Pitfalls of bone scintigraphy in suspected hip fractures. Br J Radiol. 1991;64:403-408.

4. Rizzo PF, Gould ES, Lyden JP, et al. Diagnosis of occult fractures about the hip (magnetic resonance imaging compared with bone-scanning). J Bone Joint Surg Am. 1993;75:395-401.

5. Matin P. The appearance of bone scans following fractures, including immediate and long-term studies. J Nucl Med. 1979;20:1227-1231. 